University of Nebraska - Lincoln

DigitalCommons@University of Nebraska - Lincoln

1989

REVIEW OF RADIAL DOSE MEASUREMENT TECHNIQUE AND DATA

Matesh N. Varma

U.S. Department of Energy

Follow this and additional works at: https://digitalcommons.unl.edu/usdoepub

Part of the Bioresource and Agricultural Engineering Commons

Varma, Matesh N., "REVIEW OF RADIAL DOSE MEASUREMENT TECHNIQUE AND DATA" (1989). US Department of Energy Publications. 97.

https://digitalcommons.unl.edu/usdoepub/97

This Article is brought to you for free and open access by the U.S. Department of Energy at DigitalCommons@University of Nebraska - Lincoln. It has been accepted for inclusion in US Department of Energy Publications by an authorized administrator of DigitalCommons@University of Nebraska - Lincoln. 


\title{
REVIEW OF RADIAL DOSE MEASUREMENT TECHNIQUE AND DATA
}

\author{
MATESH N. VARMA \\ U.S. Department of Energy, Washington, DC 20545, U.S.A.
}

(Received 9 January 1989)

\begin{abstract}
Radial dose is the average energy deposited in a short length of cylindrical shell formed between radii $r$ and $r+\mathrm{d} r$, per unit mass. Here, $r$ is the distance perpendicular to the trajectory of an incident charged particle. Radial dose profiles as a function of radial distance for charged particles have been used to interpret radiobiological data. This article reviews the technique for measuring radial dose distributions and the available data.
\end{abstract}

\section{INTRODUCTION}

THE CONTRIBUTION of physics to understanding the mechanisms of biological action due to exposure to ionizing radiation has been in providing the physical description of the energy deposition pattern both in time and space. One of the important physical quantities which has been recognized and used for development of biophysical models is the so-called "radial dose" distribution or profile. Dr Katz (Butts and Katz, 1976) was the leader in utilizing this concept of radial dose to actually formulate a biophysical model, which he called the "Theory of RBE". Radial dose distributions can be calculated by using either the continuous slowing down model methods or Monte Carlo techniques. However, for these calculations one must know the charged particle cross-sections. These cross-sections are generally not known for high energy heavy ions. In the late sixties and early seventies, some calculations of radial dose were made by Baum (1967), Katz and Kobetich (1968), and Chatterjee et al. (1973). Later Paretzke et al. (1976) made a much more sophisticated calculation of these quantities. Baum et al. (1968) were the first to make integral measurements for polonium alpha particles. Wingate and Baum (1976) measured differential dose distributions for protons and alpha particles over a specific energy range of $0.25-3 \mathrm{MeV} / \mathrm{amu}$. These data were the first reported measurements of radial dose; although good at the time, they had an accuracy of only $\pm 15 \%$. Baum et al. (1974), Varma et al. (1975, 1976, 1977, 1980), and Varma and Baum (1980) significantly improved the experimental apparatus used by Wingate, which resulted in the measurement of much more precise and accurate (within 2-3\%) radial doses for heavy ions over a wide range of specific energies. More recently, similar measurements have been carried out by Kanai and Kawachi (1987) and Metting (1986), who measured the

N.T. $16-2 / 3-\mathrm{E}$ fluctuations in energy deposition as a function of radial distance as well. This paper briefly describes the techniques developed at the Brookhaven National Laboratory, and summarizes the radial dose data that are available.

\section{THEORY}

Radial dose is defined as the average energy deposited per unit mass by a charged particle within a concentric cylindrical shell formed between the radii $r$ and $r+\mathrm{d} r$, where $r$ is the radial distance from the path of the charged particle. Radial dose $D(r)$ in a cylindrical section of unit length is very closely related to the stopping power $L$ as shown in equation (1)

$$
L=\int D(r) \mathrm{d} r .
$$

For all practical purposes, the upper limit of radial distance $r$ can be made equal to the maximum distance that the most energetic secondary charged particle will travel. The lower limit of the integral is somewhat arbitrary, approximating atomic dimensions. $D(r)$ can be calculated from knowledge of differential cross-sections of secondary electrons produced by charged particles. Using the experimental data available on radial dose distributions, Varma et al. (1977) obtained an empirical relationship for the radial dose distribution as given in equation (2)

$$
D(r)=\mathrm{C} \frac{Z_{\mathrm{eff}}^{2}}{E / M} \cdot 1 / r^{2},
$$

where $\mathrm{C}$ is a constant and $Z_{\mathrm{eff}}$ is the effective charge of the incident ion, $r$ is the radial distance from the trajectory of the ion, and $E$ and $M$ are the energy and mass of the ion respectively. This expression indicated that, generally speaking, the radial dose was directly proportional to the square of the effective charge of 
the incident ion and varied inversely as the square of the radial distance and the specific energy $(E / M)$.

Theoretical calculations made by Baum (1967), Katz and Kobetich (1968), Paretzke et al. (1976), Chatterjee et al. (1973) and Fain et al. (1977) all indicate dependences which are similar to those indicated in equation (2); however, some deviations do exist but since these are explained in detail in other publications, they will not be discussed here.

\section{EXPERIMENTAL TECHNIQUE AND METHOD}

The experimental apparatus consisted of a cylindrical ionization chamber with six segmented collecting electrodes placed parallel to the central axis of the cylinder, but slightly displaced. Inside this ionization chamber was placed a mesh wall ionization chamber which could be externally manipulated so that it could be placed at various distances from the central axis of the large chamber. Details on the construction and various dimensions of the apparatus have been previously published, and will not be discussed here.

When the charged particles enter the chamber they interact and produce ionization in the filling gas. This ionization current $I(r)$ is measured by the mesh ionization chamber at various distances from the path of the ions. Knowing the average energy required to produce an ion-pair $(W)$ for these ions, energy deposited in the mesh chamber can be calculated as shown in equation (3)

$$
\text { Energy deposited }=\frac{I(r)}{e} \cdot W,
$$

where $e$ is the charge of the electron.

The radial dose (which is the energy deposited per unit mass) can then be calculated as shown in equation (4)

$$
D(r)=\frac{I(r) W}{e} \cdot \frac{1}{\left(\pi r_{1}^{2} l\right)} \cdot \frac{1}{\rho_{\text {gas }}},
$$

where $r_{1}$ and $l$ are the radius and the length of the mesh probe respectively, and $\rho_{\text {gas }}$ is the density of filling gas at the experimental temperature and pressure.

The radial dose expressed by equation (4) is applicable at the radial distance given by the following expression:

$$
\text { radial distance }=\frac{r \cdot \rho_{\text {gas }}}{\rho_{\text {tissue }}} .
$$

$\rho_{\text {tissue }}$ in all our measurements has been assumed to be $1 \mathrm{~g} / \mathrm{cm}^{3} ; r$ is the physical distance from the central axis of the large ionization chamber to the central axis of the mesh chamber. Extreme care was taken in determining the saturation curves and saturation current, and wherever possible experimentally measured $W$-values were used.

More recently, using a somewhat different experimental approach which involved measurement of stochastic fluctuations in energy deposition, Metting (1986) measured the radial distributions for 13.8 MeV/amu germanium ions.

\section{RESULTS AND DISCUSSION}

Using the technique described above, the radial dose distributions for ions such as lithium, oxygen, chlorine, bromine, iodine, neon, helium, and protons, in the specific energy range from a few tenths of a $\mathrm{MeV} / \mathrm{amu}$ to several hundred $\mathrm{MeV} / \mathrm{amu}$ have been measured. Table 1 lists the ions, their specific energy, and the investigator making the measurements, for which measurements have been made and published. Most of the measurements at low specific energies were made at the Brookhaven National Laboratory using the Tandem VandeGraff, whereas high specific energy measurements were made at the 184-inch cylotron and BEVALAC at Berkeley. Recently, measurements with germanium ions were made on the heavy-ion machine at GSI Darmstadt.

Waligorski et al. (1986) have used most of the data of Varma et al. on radial dose distribution and have developed an empirical analytical function which calculates the radial dose distribution as a function of distance for a wide range of ions and energies. Figure 1 shows a comparison of this analytical calculation with measurements of Varma et al. Figure 2 shows a comparison of Katz's calculation with more recent measurements of Kanai and Kawachi (1987). It is very encouraging to note that at most of the energy range and radial distances, the measurements and calculations agree reasonably well. A similar comparison of radial distributions calculated from Varma et al. (1977) and the measurements made by Metting (1986) also show a reasonably good agreement (within a factor of two), as shown in Fig. 3.

One conclusion that emerges from all these measurements and calculations is that, for the most part, the radial dose varies directly as the square of the effective charge and inversely as the square of radial distance and the specific energy. However, at radial distances very close to the trajectory of the incident ion, substantial discrepancies between the calculations and experimental measurements continue to exist. Since the contribution to total dose could be significant at small radial distance, this

Table 1. Ions and their specific energies for which radial dose profiles have been measured, and the investigators making the measurement

\begin{tabular}{ccc}
\hline Ion & Specific energy $(\mathrm{MeV} / \mathrm{amu})$ & Investigator \\
\hline Proton & 1 and 3 & Baum et al. \\
${ }^{4} \mathrm{He}$ & 0.75 and 230 & Varma et al. \\
${ }^{16} \mathrm{O}$ & 2.4 & Varma et al. \\
${ }^{127} \mathrm{I}$ & 0.26 and 0.49 & Varma et al. \\
${ }^{20} \mathrm{Ne}$ & 377 & Varma et al. \\
${ }^{79} \mathrm{Br}$ & 0.53 & Varma et al. \\
${ }^{4} \mathrm{He}$ & 18.3 & Kanai et al. \\
${ }^{72} \mathrm{Ge}$ & 13.8 & Metting et al. \\
\hline
\end{tabular}



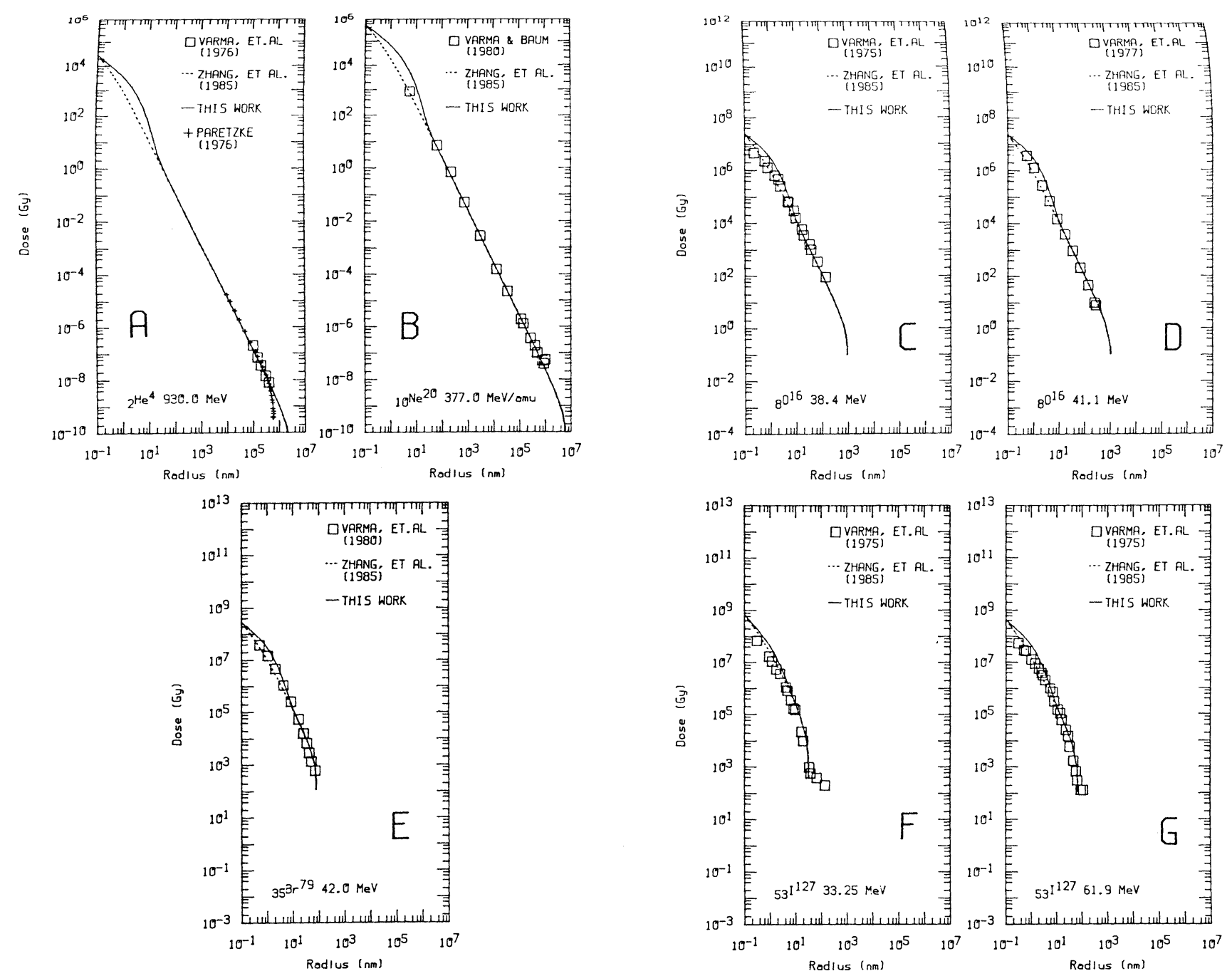

Fig. 1. Comparison of calculated radial dose distributions calculated by Katz and others with the Varma et al. (1977) measurements for various ions and energies [Zhang et al. (1985); Waligorski et al. (1986)]. 


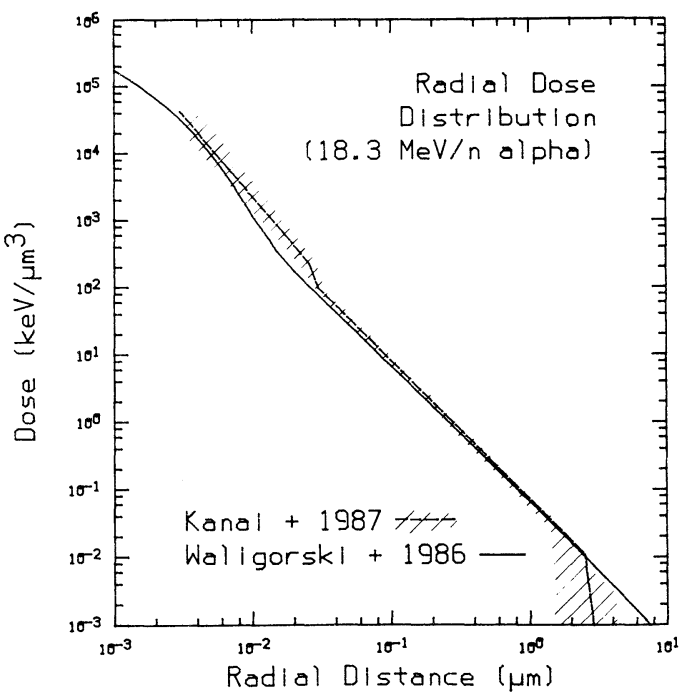

Fig. 2. Comparison of the Waligorski et al. calculation of radial dose distributions for $18.3 \mathrm{MeV} / \mathrm{amu}$ alpha particles with the measurements of Kanai (1987).

discrepancy could affect the interpretation of radiobiological effect in a very significant manner, therefore studies aimed at furthering our understanding in this area should be of top priority. Discrepancy at very large distances is also significant, and could play an important role in testing some of the assumptions made in biophysical models, and also in comparison with experimental findings in the "thin down" region found with slowing very heavy ions.

An indirect way to compare quantitatively experimental and calculated values of the maximum radial extent to which energy is deposited by the extremely high energy (a few hundred $\mathrm{MeV} / \mathrm{amu}$ ) heavy ions, is to compare calculated and measured linear energy transfer restricted in distance $\left(\mathrm{LET}_{r}\right)$ at the largest measured radial distance. This comparison was made for $377 \mathrm{MeV} / \mathrm{amu}$ neon ions. The ratio of $\mathrm{LET}_{r}$ to LET at a distance of 174 microns (the maximum radial distance at which measurement was made) was calculated by Magee and Chatterjee (1980) to be 1.0 , whereas the experimentally measured ratio was 0.942 . This suggests that the maximum radial distance, if it could be measured experimentally, would be higher than that predicted by these calculations.

Acknowledgments - I am indebted to Dr L. Toburen for the calculations and comparisons shown in Fig. 3.

\section{REFERENCES}

Baum J. W. (1967) Comparison of distance and energyrelated restricted energy transfer to heavy particles with 0.25 to $1100 \mathrm{MeV} / \mathrm{amu}$. Brookhaven National Laboratory, internal report.

Baum J. W., Stone S. L. and Kuehner A. V. (1968) Radial distribution of dose along heavy ions tracks, LET . In Proc. Symp. Microdosim., Ispra, Italy (Edited by Eberg H. G.), pp. 269-281.

Baum J. W., Varma M. N., Wingate C. L., Paretzke H. G. and Kuhner A. V. (1974) Nanometer dosimetry of heavy ion tracks. In Proc. 4th Symp. Microdosim., Verbania Pallanza, Italy (Edited by Booz J. and Ebert H. G.), Vol. 1, pp. 93-112. EUR 5122 d-e-f.

Butts J. J. and Katz R. (1976) Theory of RBE for heavy ion bombardment of dry enzymes and viruses. Radiat. Res. 30, 855-871.

Chatterjee A., Maccabee H. D. and Tobias C. A. (1973) Radial cut-off LET and radial cut-off dose calculations for heavy charged particles in water. Radiat. Res. 54, 479-494.

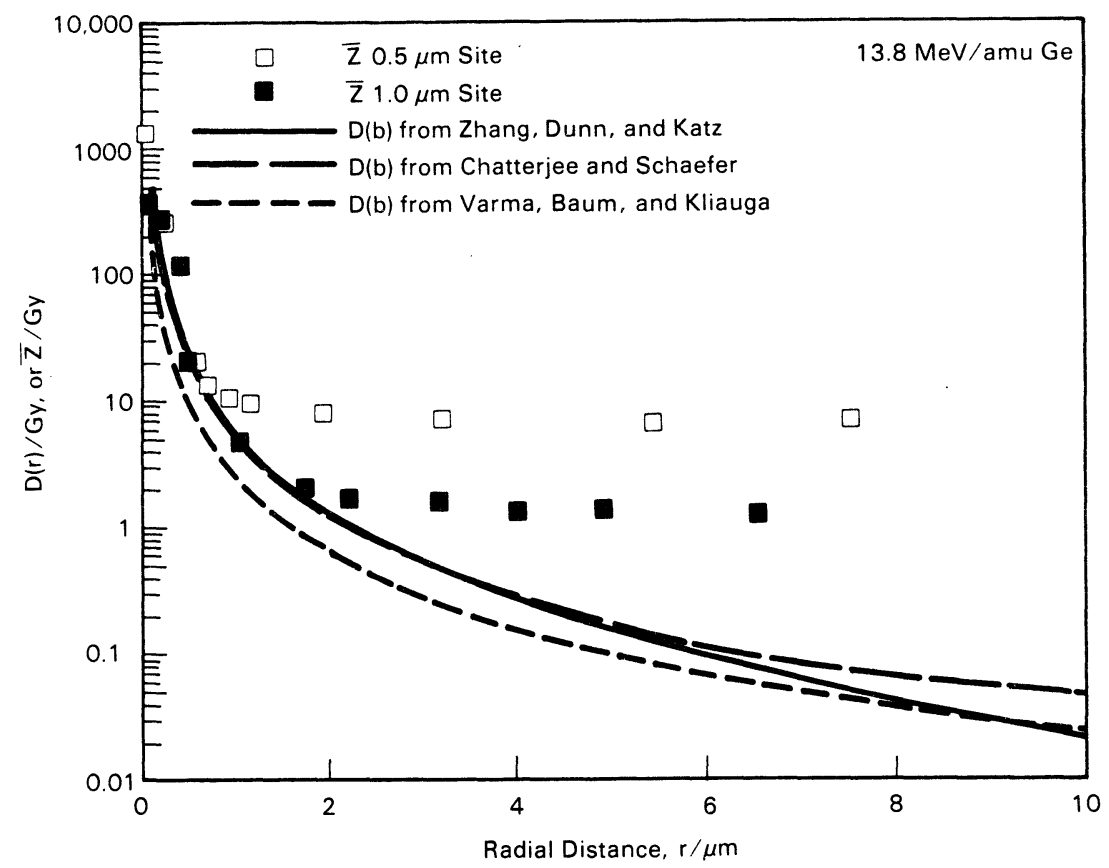

Fig. 3. Comparison of radial dose distributions calculated from Varma et al. (1977), and the measurements of Metting (1986). 
gin J., Monnin M. and Montret M. (1977) Spatial energy distribution around heavy ion paths. Radiat. Res. 57, 379-389.

(anai T. and Kawachi K. (1987) Radial dose distribution for $18.3 \mathrm{MeV} / \mathrm{n}$ alpha beams in tissue equivalent gas. Radiat. Res. 112, 426-435.

satz R. and Kobetich E. J. (1968) Energy deposition by electron beams and delta rays. Phys. Rev. 170, 391-396.

vagee J. L. and Chatterjee A. (1980) Radiation chemistry of heavy particle tracks. I. General considerations. J. phys. Chem. 84, 3529-3336.

vetting N. F. (1986) Measurement of energy deposition near high energy heavy ion tracks. Doctoral thesis, Pacific Northwest Laboratory, Richland, WA.

paretzke H. G., Leuthold G., Burger G. and Jacobi W. (1976) Approaches to physical track structure calculations. In Proc. 4th Symp. Microdosim., Verbania Pallanza, Italy (Edited by Booz J., Ebert H., Eickel R. and Walker A.), Vol. 1, pp. 127-139. EUR 5452 d-e-f. ırma M. N., Baum J. W. and Kuehner A. V. (1975) Energy deposition by heavy ions in a "tissue equivalent" gas. Radiat. Res. 62, 1-11.

arma M. N., Paretzke H. G., Baum J. W., Lyman J. T. and Howard J. (1976) Dose as a function of radial distance from a $930 \mathrm{MeV}{ }^{4} \mathrm{He}$ ion beam. In Proc. 5th Symp. Microdosim., Verbania Pallanza, Italy (Edited by Booz J., Ebert H. G. and Smith B. G. R.), Vol. 1, pp. 75-79. EUR 5452 d-e-f.

Varma M. N., Baum J. W. and Kuehner A. V. (1977) Radial dose, LET and $\mathrm{W}$ for ${ }^{16} \mathrm{O}$ ions in the $\mathrm{N}_{2}$ and tissue equivalent gases. Radiat. Res. 70, 511-518.

Varma M. N. and Baum J. W. (1980) Energy deposition in nanometer regions by $377 \mathrm{MeV} /$ nucleon ${ }^{20} \mathrm{Ne}$ ions. Radiat. Res. 81, 355-363.

Varma M. N., Baum J. W. and Kuehner A. V. (1980) Stopping power of radial dose distribution for $42 \mathrm{MeV}$ bromine ions. Physics Med. Biol. 25, 651-656.

Waligorski M. P. R., Hamm R. N. and Katz R. (1986) Radial distribution of dose around the path of a heavy ion in liquid water. Nucl. Tracks Radiat. Meas. 11, 309-319.

Wingate C. L. and Baum J. W. (1976) Measured radial distribution of dose and LET for alpha and proton beams in hydrogen and tissue-equivalent gas. Radiat. Res. 65, 1-17.

Zhang C., Dunn D. E. and Katz R. (1985) Radial distribution of dose and cross-section for the inactivation of dry enzymes and viruses. Radiat. Prot. Dosim. 13, 215-218. 